\title{
Challenges for extending radiology services during COVID-19 pandemic
}

All of us in various medical posts be it clinical or administrative have never really encountered such a situation in our entire life time. World was awakened by an unknown highly infectious virus "CORONAVIRUS" (COVID- 19/ SARS-COV-2). Yes, it was a PANDEMIC which we were looking at. Thus realised that it would be a humongous challenge providing radiological services especially since the important factors like number of patients, symptomatology and severity of disease were unknown.

It originated from Wuhan in China and India started getting international passengers with a looming arrival of pandemic. Initially we got concerned to hear about the initial cases in India. It was unreal to watch doctors and paramedics treating patients in PPE on television/social media. But when we started hearing about the first case in Mumbai and finally the first case in our hospital, that we started getting the feeling that it's really close now and knocking on our doors, April first week. Situation changed drastically in April when patients started pouring in like a deluge of the Mumbai monsoon.

LTMG Hospital is one of the few tertiary care providers in Mumbai having 1900 beds and we had to gear up for the upcoming challenge. As always in any crisis, this time also all branches and faculties along with all paramedics under the guidance of all HODs, Dean, Director and Hon. Municipal commissioners started working for it. Every step was learning step for all the faculties.

\section{Infection Control}

Being a non-designated Covid hospital like all other branches we also had to cater to both Covid and non-Covid patients. So, the mammoth task was to avoid mixing of all these patients and not to become an epicentre of disease spread. Initially only Chest X-ray was the imaging modality which was useful in management of disease. So, to avoid transport of Covid patients to X-ray department and mixing with non-Covid patients, we decided to provide compulsory portable X-ray services for all Covid positive patients.

Various guidelines, data and literature about Covid and radiology were available on internet which was changing rapidly. Available treatment guidelines were also evolving. So, apart from bedside X-ray, HRCT chest and CT pulmonary angiography was recommended. Here also we had to avoid mixing of Covid patients with non-Covid patients. We planned to do CT scans of all Covid patients at a fixed time interval initially every alternate day and then every day. We decided to do this in evening hours to avoid all OPD timings and crowd. Non-Covid patient or their relatives were not allowed to wait in premises or waiting area of CT scan during this time.

\section{Equipment}

Being in a large public hospital and as regards to radiology services the challenges doubled in terms of machinery. As the cases started increasing and more wards started getting converted to Covid wards, the challenge was to provide portable X-ray machines followed by a prompt digital images or radiograph. In April only ground floor was having dedicated Covid wards so we provided one portable X-ray machine for it.

But the number of patients kept increasing and thus the number of Covid wards and floors having Covid wards kept increasing. But we handled second challenge also by providing separate portable X-ray machines for every floor of hospital. Providing this was not a major problem because being a large hospital we had the machinery and number of 
non-Covid patient were significantly less. We could mobilise portable X-ray machines from currently less required areas like orthopaedic OT to Covid wards.

\section{Procurement}

But while doing this, after taking the X-ray the Radiology technician had to come to X-ray department for reading the cassette and to take a digital X-ray print. So our next challenge was to procure a CR system which could be kept in ward building not only to get a prompt digital image and radiograph film but also to avoid movement of technicians into non-Covid areas for developing these radiographs. Procuring this CR system was not easy being a public hospital with multiple permissions required. Fortunately, this was possible at a faster speed in view of the pandemic. Expenditure power of Dean was raised by the concerned authorities. It was a very helpful decision as Dean knew about the current problems in their hospitals and they could take decisions at earliest and give us the permissions.

\section{Surface Disinfection and Air Exchange}

To avoid surface contamination of cassettes, before entering the Covid ward we asked them to cover the cassette with 2 green sheets. After taking the X-ray outer green sheet was discarded in Covid ward only and the inner green was discarded in CR system room. Then the cassette was cleaned with alcohol based solution just before putting the cassette in CR system for developing radiographs.

Initially there was no consensus towards, how to fumigate the CT gantry room with no particular standardization and no proper guidelines from the manufacturers. We developed our own protocol after little bit research on internet, attending few webinars and according to material available to us. We did surface cleaning of table and gantry with alcohol based solution after each patient and surface disinfection of entire CT scan department with sodium hypochlorite after the last patient. We also kept a window period of 1 hour for sufficient air exchange before starting non-Covid patient's CT scan.

\section{Protecting the Covid Warriors}

Apart from this one major obstacle was to take care of our COVID WARRIORS which includes all doctors, technicians, sisters, clerical staff and servants. Due to a generalised fear about Covid in society we had to keep their morale high. LTMG Hospital in its history saw and handled medical emergencies like riots and blasts very well multiple times. But this situation was different as the care giver was at highest risk of contracting infection. We provided PPE kits, N95 masks and hydroxycholoroquine tablets for prophylaxis to all of them. We also mobilised alcohol-based hand sanitizers to be kept in each room of department and also mobilised stands with foot pad for sanitizers which were kept at entry of each section of department. Since it was an out of the blue situation for administration also, we had to mobilise all this from donors time to time to avoid scarcity of supply. For which we are thankful to all our generous donors.

Despite this our many warriors contracted Covid infection but during these tough times we took care of them. We got them admitted in our hospital only and provided them proper treatment, which boosted the morale of other employees also.

\section{Special Protection of X-Ray Technicians}

Unlike technicians and doctors in CT scan, technicians working in X-ray department were in contact of Covid patients for a longer time and had to go in Covid wards more frequently. We trained them to minimise contact with patient and to quickly position the cassette below patient. Multiple videos available on social media were shown to them on their mobile phones as we could not conduct a class for them for it. We also provided them small bottles of alcohol based hand sanitizers to be kept in pocket and to use them whenever required. We made sure that there is no shortage of PPE to these technicians and they were always given first preference during PPE distribution of department.

\section{Logistics}

Due to lockdown and lack of transportation facility, we had to arrange for stay for those who were staying far away. This task was made easy due to help from various hotels like Taj and Renaissance who provided their rooms to our employees. With all local trains shut down, BEST and State Transport bus authority helped our employees for transportation that too with maintaining the social distancing norms.

\section{Extending Manpower Help}

With government setting up Covid Care Centres one more challenge we had was to mobilise manpower i.e., doctors and technicians in these facilities. It was made easy as our exam going resident doctors and technician were ready for it as and when needed. This helped us keeping the central department running with full strength.

\section{Academics during Lockdown}

With implementation of social distancing norms, we had to curb all the clinical and educational meeting with various departments like medicine, neurology, respiratory medicine, surgery, gastroenterology, paediatric surgery, etc. Non-Covid cases coming to hospital suddenly dropped and residents started thinking that these months are wastage of precious time of their residency and they won't be able to see variety of cases. But we still continued our academic work. We started weekly online teaching sessions for residents on platforms like Zoom and Google meet. 
With such a large data of Covid cases available to us, our 3-4 articles are in the process of writing and publication.

\section{Final Words}

This pandemic has made us a little wiser as regards to both administrative and clinical challenges. The end of pandemic is still out of sight, maybe we are only half way through, but looking back the past 6 months, it has been a humbling experience to be able to render our services, since we are a service provider branch.

\section{Financial support and sponsorship}

Nil.

\section{Conflicts of interest}

There are no conflicts of interest.

\section{Anagha R Joshi, Vikrant P Firke, Vivek K Ukirde}

Department of Radiology, Lokmanya Tilak Municipal Medical College and General Hospital, Sion, Mumbai, Maharashtra, India. E-mail: drfirkevikrant@yahoo.co.in
This is an open access journal, and articles are distributed under the terms of the Creative Commons Attribution-NonCommercial-ShareAlike 4.0 License, which allows others to remix, tweak, and build upon the work non-commercially, as long as appropriate credit is given and the new creations are licensed under the identical terms.

\begin{tabular}{|c|c|}
\hline \multicolumn{2}{|c|}{ Access this article online } \\
\hline Quick Response Code: & \\
\hline & $\begin{array}{l}\text { Website: } \\
\text { www.ijri.org }\end{array}$ \\
\hline & $\begin{array}{l}\text { DOI: } \\
\text { 10.4103/ijri.IJRI_749_20 }\end{array}$ \\
\hline
\end{tabular}

Cite this article as: Joshi AR, Firke VP, Ukirde VK. Challenges for extending radiology services during COVID-19 pandemic. Indian J Radiol Imaging 2021;31:S213-5.

Received: 11-Sep-2020 Revised: 21-Sep-2020

Accepted: 02-Jan-2021 Published: 23-Jan-2021

๑ 2021 Indian Journal of Radiology and Imaging | Published by Wolters Kluwer - Medknow 